\title{
QCM SENSOR SENSITIVITY ANALYSIS OF SILVER ELECTRODES COATED WITH LIPID MEMBRANE OLEYL ALCOHOL TOWARD NaCl AND HCl
}

\author{
Auliya Rahmatul Ummah', Imam Tazi*2, Muthmainnah ${ }^{3}$ \\ ${ }^{1-3}$ Physic Department, Universitas Islam Negeri Maulana Malik Ibrahim Malang \\ Gajayana St. No. 50 Malang 65144
}

\begin{abstract}
One of the sensors, which is currently being developed is the QCM sensor. The QCM sensor is a sensor that utilizes the frequency change to detect a change in mass due to a test substance. The use of a QCM sensor includes other forms of electronic tongue sensor that can distinguish five basic flavours on the tongue. QCM sensor can also be varied electrodes using various lipid membranes such as electronic tongues to increase sensor sensitivity. This research aims to determine the sensitivity of the QCM sensor before and after coated with lipid membrane to $\mathrm{NaCl}$ and $\mathrm{HCl}$. The sensitivity of the QCM sensor to $\mathrm{NaCl}$ is $1.47 \mathrm{~Hz} / \mathrm{M}$ for uncoated sensor and $0.63 \mathrm{~Hz} / \mathrm{M}$ for coated sensor, while the sensitivity of $\mathrm{HCl}$ is $4.55 \mathrm{~Hz} / \mathrm{M}$ for uncoated sensor and $4.93 \mathrm{~Hz} / \mathrm{M}$ for coated sensor. The difference of the results is caused by the nature of ionization of the compound and the amount of concentration used. The result of the sensitivity research shows that the QCM sensor with Oleyl Alcohol lipid membrane is more sensitive to $\mathrm{HCl}$ than $\mathrm{NaCl}$.
\end{abstract}

Keywords: QCM Sensor; Oleyl Alcohol; Sensitivity; $\mathrm{NaCl} ; \mathrm{HCl}$

\section{Introduction}

Sensor technology has been experienced in very rapid development. Various sensors were created to ease the people activities. Some of them also created to replace the role of organs in the human body in order to avoid harmful materials. Sensors that can replace the functions of human organs include electronic tongue sensors, electronic nose sensors and electronic eyes sensors. The sensors were developed to meet the limitations of the human body. ${ }^{1}$

Human organs that need to be protected and have limitations are the five human senses. One of the five senses that can directly interact with chemicals is a tongue. The human tongue has a threshold in detecting basic tastes and susceptible to damage when exposed to harmful substances. That problem is the reason for assembling electronic tongue sensor. Various sort of electronic tongue sensor have been

\footnotetext{
*orresponding author

E-Mail: tazimam1974@gmail.com
}

developed including Quartz Crystal Microbalance sensor (QCM). ${ }^{2}$

QCM sensor is made of AT-cut quartz crystal pieces. There are electrodes on the upper and lower sides of the sensor as well as holders that connect it to the processor. The working principle of the QCM sensor is it is vibrated by an oscillator so it vibrates stably. Effect of Inverse-piezoelectric works in testing QCM sensors cause deformation and generates an electric field. Oscillation frequency on the sensor is calculated by the frequency counter through the electric field. ${ }^{2}$ QCM sensors utilize the change in oscillation frequency value to determine the change in mass substance. This is shown in the Sauerbrey equation as follows ${ }^{3}$ :

$\Delta f=\frac{-C_{f} f_{0}^{2} \Delta m}{A}$

The use of QCM sensors is another form of electronic tongue sensor because it can be used for liquid samples. Sensor electrodes 
can also be varied by coating other compounds such as lipid membranes and polymers. This study used the lipid Oleyl Alcohol membrane to increase sensor selectivity. The use of these membranes is based on research carried out by Al Jazuly in testing the taste of the tongue using an $e$ tongue sensor. ${ }^{4}$

There are five basic flavours on the tongue; sweet, sour, salty, bitter and savoury taste (umami). This study used $\mathrm{NaCl}$ test material to represent the salty taste and $\mathrm{HCl}$ to represent the sour taste. Testing salty taste with sensors is needed because the determination of salt quality standards in Indonesia could not be done directly with the human tongue. Acid testing also could not be detected directly by the tongue because strong acids can damage the tongue's organs. 5,6

In this study, testing of salty and sour taste was carried out by using varied electrode QCM sensor. Electrodes used to test $\mathrm{NaCl}$ and $\mathrm{HCl}$ are pure silver and coated Oleyl Alcohol lipid membrane layer electrodes. Membrane coating aimed to protect sensor electrodes and increase sensor selectivity. The technique used to coat the sensor is a spin coating technique. It is a material coating method using the centripetal force on the material to get a layer that is evenly distributed on the entire surface. ${ }^{7}$

QCM sensor could not be operated without a series of processors. Its processor circuit consists of an oscillator, microcontroller and frequency counter. This study used open-QCM for examination. It is found a micro Arduino as a microcontroller and frequency counter along with an Arduino shield QCM as an oscillator in open-QCM. Open-QCM series was also integrated with the open-QCM 1.2 software that can display the sensor oscillation frequency output in real-time so it is easy to use. ${ }^{8}$

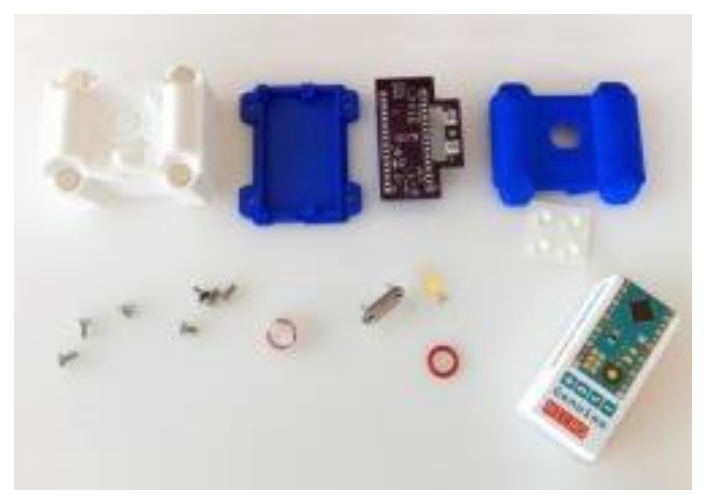

Figure 1. Open-QCM series

\section{Methods}

In this study, the data were gained through three stages; preparation, sample testing, and data processing stage. Preparation stage included membrane coating and sample measurement. Membrane coating on the surface of the QCM sensor electrode uses the spin coating method. Oleyl Alcohol lipid membrane is made of three main components; $3 \%$ lipids, $32 \%$ PVC and 65\% plasticizers. ${ }^{9}$ QCM sensor that is used has crystal resonator with a diameter of $8.90 \mathrm{~mm}$, HC-49/U holder, and silver electrode with a diameter of $5.1 \mathrm{~mm}$.

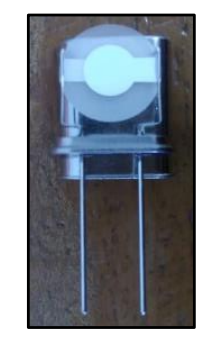

Figure 2. QCM HC-49/U Sensor

Measurement of sample test using two methods: dissolution and dilution. Dissolution was carried out on $\mathrm{NaCl}$ crystal using equation (2). The amount of $\mathrm{NaCl}$ concentration tested was 20 concentrations of $100 \mathrm{mM}-2000 \mathrm{mM}$ at intervals of $100 \mathrm{mM}$. Dilution method was carried out on $32 \%$ concentrated $\mathrm{HCl}$ samples by using equation (3). There were 10 concentrations of $\mathrm{HCl}$ tested between 100-550mM. $\mathrm{HCl}$ concentration interval was $50 \mathrm{mM}$. The amount of $\mathrm{HCl}$ concentration is not the same as $\mathrm{NaCl}$ because of the nature of $\mathrm{HCl}$ is a 
strong acid. A too-high $\mathrm{HCl}$ testing in concentration can cause corrosion on QCM holder.

$$
\begin{aligned}
& M=\frac{m}{M r} \times \frac{1000}{V} \\
& V_{1} \cdot M_{1}=V_{2} \cdot M_{2}
\end{aligned}
$$

The sensor testing phase carried out by testing the sensor's basic frequency. Basic frequency is the frequency on the sensor before being subjected to the sample. Basic frequency testing aims to control the sensor when changing the concentration of the test sample. Both types of sensors are vibrated for five minutes with five times repetitions. Then, data from basic frequency is averaged to become a reference for further testing. Testing of $\mathrm{NaCl}$ and $\mathrm{HCl}$ samples was carried out after the basic frequency is determined. Samples were dropped on the surface of the QCM sensor as much as $100 \mu \mathrm{L}$ using a micropipette drop. The duration of testing is five minutes with five repetitions. Each repetition produces 300 data. Analysed data is the last 200 data because the data is a stable state of the sensor.

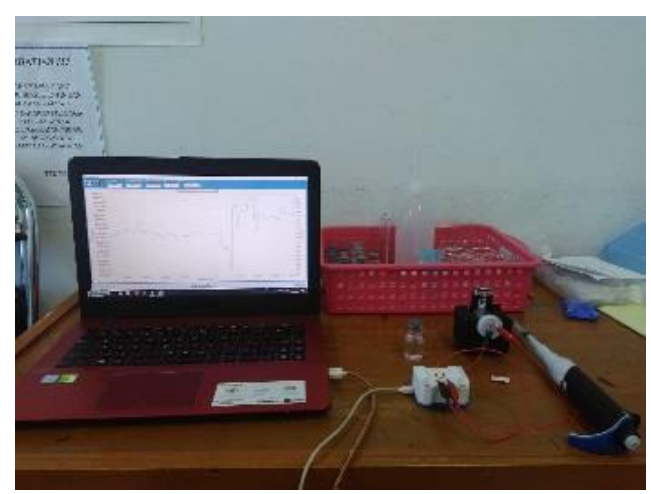

Figure 3. QCM sensor testing process

Afterwards, oscillation frequency data obtained is averaged in the last 200 data and analysed by sensor sensitivity. The data processing stage is done using the Origin-Pro 2017 software. Sensor sensitivity is obtained by linear regression of the relationship between sample concentration and oscillation frequency. Linear regression analysis will show slope, intercept and analysis of errors in the data. Determination of sensor sensitivity aims to determine the sensor's ability to detect changes in the test material.

\section{Result and Discussion}

Sensitivity is one of the characteristics that sensor users must know. Sensitivity value is a value that shows the ability of the sensor response when a sample changes are tested. Sensor sensitivity analysis was performed by linear curve regression analysis of the relationship between sample concentration and sensor oscillation frequency. Linear regression is determined by the transfer function of a curve shown in equation (4).

$y=a \pm b x$

Sensitivity value is shown in the value $b$ in equation (4). The value $b$ shows the slope curve. Sensor sensitivity towards input changes is indicated by the slope curve value. Linear regression is performed on the curve of the sensor work area. Work area compared between the two sensors must be equalized. Sensitivity analysis of the QCM sensor on $\mathrm{NaCl}$ testing is at a concentration of 1000 $\mathrm{mM}-2000 \mathrm{mM}$, while the $\mathrm{HCl}$ test is at a concentration of 250-550 mM.

Linear regression results of $\mathrm{NaCl}$ testing with pure silver QCM sensor $(\mathrm{y}=1.40553 \mathrm{E} 7$ - 1468.96871x) as in figure 4. The equation shows that the sensor sensitivity value is $1468.96 \mathrm{~Hz} / \mathrm{mM}$. The regressed work area adapts to the sensor work area with the membrane because the ratio must be the same.

There was a decreasing on Sensor oscillation frequency value along with increasing sample concentration. Oscillation frequency has increased at a concentration of $1100 \mathrm{mM}$ and $1900 \mathrm{mM}$, yet it is back to decrease in the next concentration. So, the slope is higher than coated QCM sensor. Sensor output values in $\mathrm{HCl}$ testing with uncoated membrane are in the frequency range between $12.6 \mathrm{MHz}-10.8 \mathrm{MHz}$ changes 
in sensor output indicate that the sensor can respond to changes in the concentration of the tested sample.

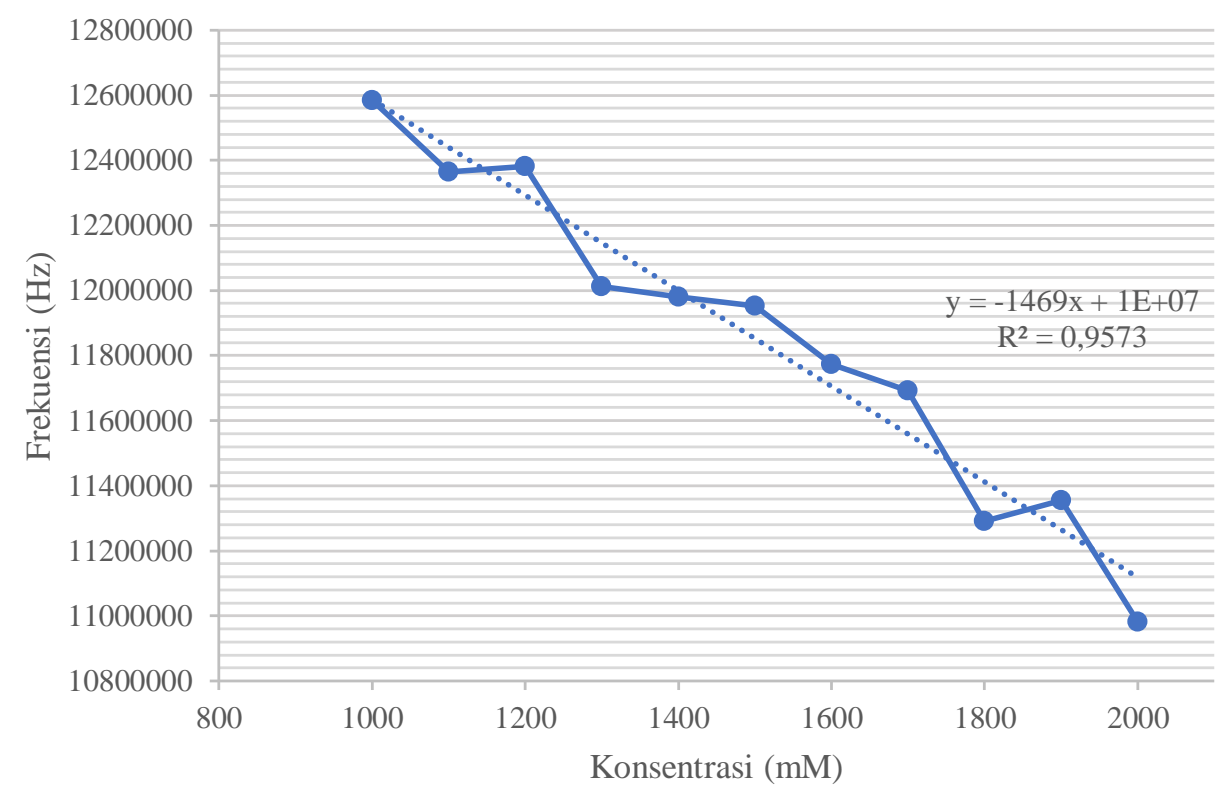

Figure 4. Analysis of uncoated QCM Sensor Sensitivity on $\mathrm{HCl}$

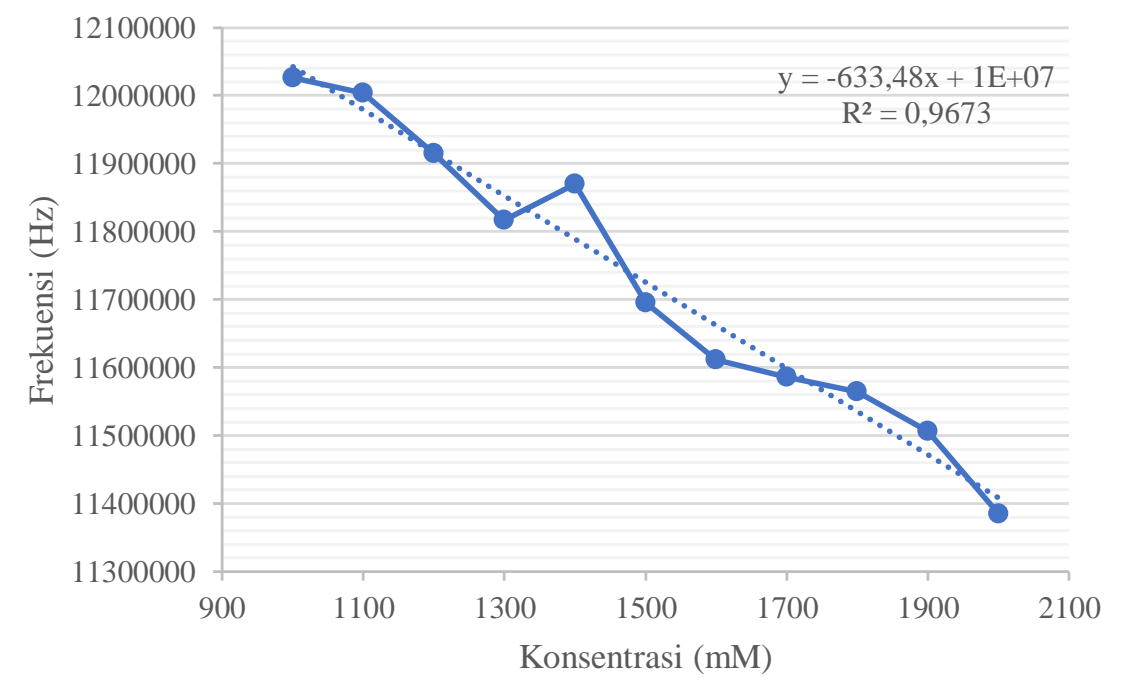

Figure 5. Analysis of Coated QCM Sensor Sensitivity on $\mathrm{NaCl}$

Linear regression curve of coated QCM sensor test results in $\mathrm{NaCl}$ sample is shown in Figure 5. Its equation is $\mathrm{y}=1.26753 \mathrm{E} 7$ 633.48473x. Sensitivity value of the regression curve is $633.48 \mathrm{~Hz} / \mathrm{mM}$. Coated QCM sensor sensitivity in Figure 5 is smaller when compared to the uncoated one.
Figure 6 shows the results of sensitivity analysis of pure silver QCM sensor electrodes in $\mathrm{HCl}$. Linear regression equation obtained is $\mathrm{y}=1.37025 \mathrm{E} 7-4545.00315 \mathrm{x}$. Sensitivity analysis of sensors in $\mathrm{HCl}$ testing showed very different results. Sensitivity values obtained are much greater than $\mathrm{NaCl}$. 
The sensitivity of the uncoated QCM sensor in $\mathrm{HCl}$ testing is $4545 \mathrm{~Hz} / \mathrm{mM}$. There is a difference in sensitivity values of $\mathrm{NaCl}$ and $\mathrm{HCl}$ testing was caused by differences in the concentration of the sample used. $\mathrm{NaCl}$ concentration tested was greater than $\mathrm{HCl}$ concentration so that the sensor response was lower than $\mathrm{HCl}$.

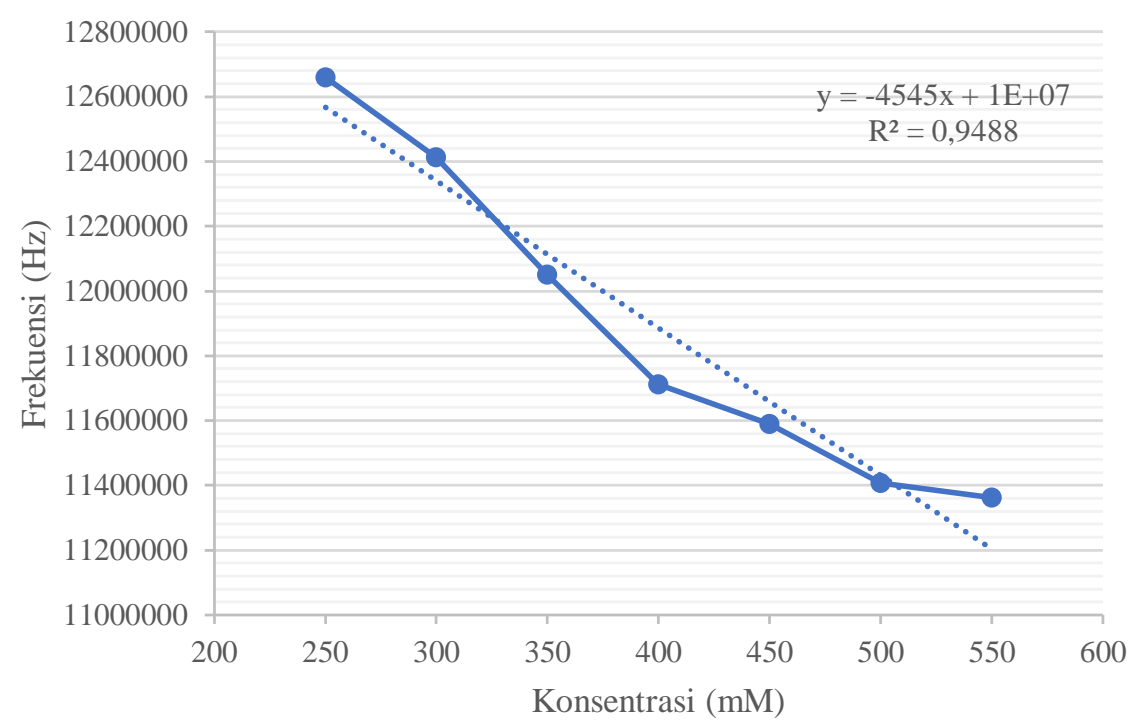

Figure 6. Analysis of uncoated QCM Sensor Sensitivity on $\mathrm{HCl}$

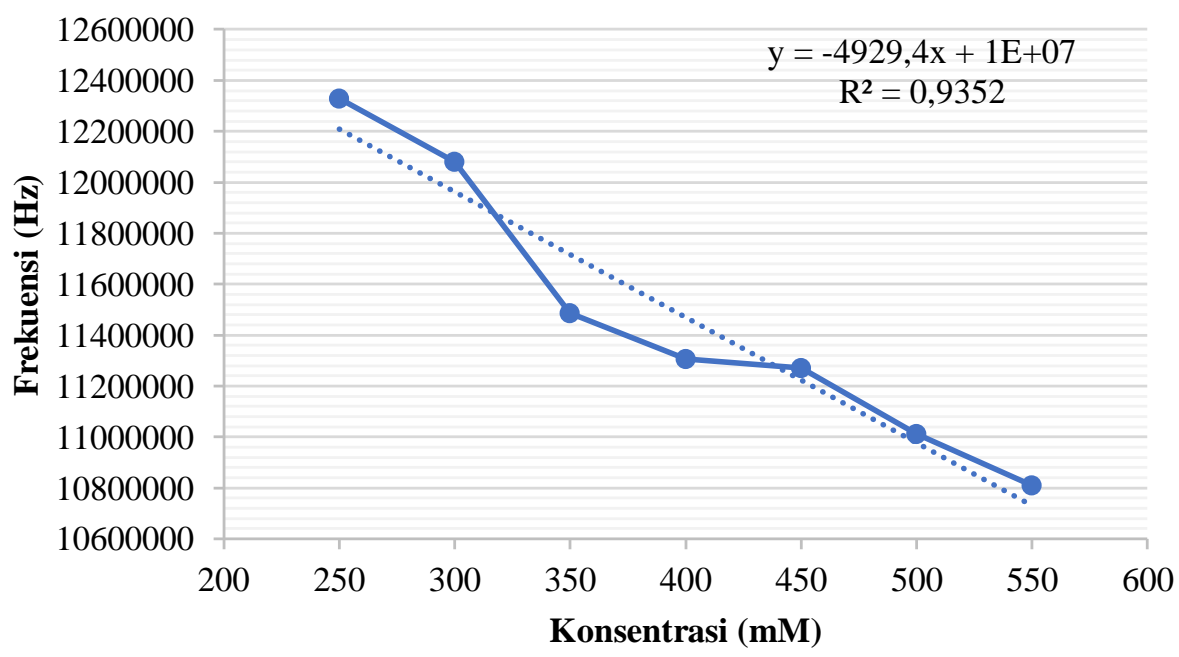

Figure 7. Analysis of Coated QCM Sensor Sensitivity on $\mathrm{HCl}$

Coated QCM sensor testing in $\mathrm{HCl}$ has a working area between concentrations of 250 $\mathrm{mM}-550 \mathrm{mM}$. Regression analysis of linear work area curves is shown in Figure 7. Linear regression equation obtained is $\mathrm{y}=$ 1.34423E7 - 4929.41032x. Sensor sensitivity that is obtained from $\mathrm{HCl}$ testing was 4929.4 $\mathrm{Hz} / \mathrm{mM}$. This value is higher than the uncoated QCM sensor. Then, it is gained overall data from the sensor sensitivity testing analysis. It is shown in table 1. 
Table 1. Result of Sensitivity Analysis

\begin{tabular}{lcccc}
\hline \multirow{2}{*}{ Electrode Sensor } & \multicolumn{2}{c}{ NaCl } & \multicolumn{2}{c}{ HCl } \\
\cline { 2 - 5 } & $\begin{array}{c}\text { Sensitivity } \\
(\mathbf{H z} / \mathbf{M})\end{array}$ & $\mathbf{R}^{\mathbf{2}}$ & $\begin{array}{c}\text { Sensitivity } \\
(\mathbf{H z} / \mathbf{M})\end{array}$ & $\mathbf{R}^{\mathbf{2}}$ \\
\hline Silver (Pure) & 1.47 & 0.96 & 4.55 & 0.95 \\
Coated Silver & 0.63 & 0.98 & 4.93 & 0.93 \\
\hline
\end{tabular}

Coated QCM sensor sensitivity is higher on $\mathrm{HCl}$ testing. It caused by protonation interactions occurs between membranes and $\mathrm{HCl}$. Protonation interaction is the binding ability of protons from a compound binding to other compounds. Oleyl alcohol lipid membrane has a chemical structure $\mathrm{C}_{18} \mathrm{H}_{36} \mathrm{O}$. The structure is a long hydrocarbon chain with an outer functional group in the form of $\mathrm{OH}$. The $\mathrm{C} 18 \mathrm{H} 36 \mathrm{O}$ chain is shown in Figure 8.

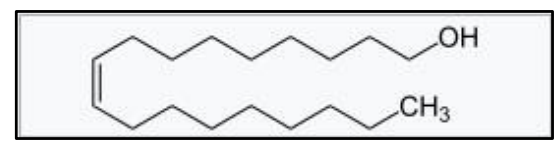

Figure 8. Chain of Oleyl Alcoholic Hydrocarbon

Protonation interactions are caused by $\mathrm{OH}$ groups that change to $\mathrm{O}-$ and $\mathrm{H}+$ when they meet a sample test. Protons from $\mathrm{NaCl}$ and $\mathrm{HCl}$ will be bound by $\mathrm{O}$-ions so that they are absorbed by the membrane and cause changes in the sensor mass. The change in mass causes changes in the frequency of sensor oscillations. Oscillations sensor frequency is decreased along with the increasing of concentration. The greater the concentration of the test sample, the greater the mass bound by the membrane and the more difficult to vibrate. This causes the number of oscillation sensor frequencies to become inversely proportional to concentration sample. Sensitivity value of coated QCM sensors on $\mathrm{HCl}$ is higher than $\mathrm{NaCl}$ due to the differences in concentration and ionization level of compounds. $\mathrm{HCl}$ is a strong acid which is very reactive when interacting with oleyl alcohol lipid membranes, in addition the concentration of
$\mathrm{HCl}$ is smaller than $\mathrm{NaCl}$ so that it is more easily vibrated by the sensor.

\section{Conclusion}

In $\mathrm{NaCl}$ testing, Uncoated QCM sensor sensitivity is higher than the coated ones. Meanwhile, in $\mathrm{HCl}$ testing, it is found that coated QCM sensor sensitivity is higher than the uncoated one because of the presence of strong acid ions in $\mathrm{HCl}$ which are more reactive to the membrane. It caused by ionization properties of $\mathrm{HCl}$ which is more reactive to lipid oleyl alcohol membrane than ionization properties of $\mathrm{NaCl} . \mathrm{HCl}$ concentration is smaller than $\mathrm{NaCl}$ so that $\mathrm{HCl}$ is more easily vibrated by the sensor. This study showed that lipid oleyl alcoholic membrane on the QCM sensor is more appropriate for testing $\mathrm{HCl}$ rather than $\mathrm{NaCl}$. Coated QCM sensor sensitivity for $\mathrm{HCl}$ testing is three folds higher than $\mathrm{NaCl}$ testing with a response time of $15 \mathrm{~s}$.

\section{References}

1. Rattanawarinchai $\mathrm{P}$, Krongkrachang $\mathrm{P}$, Chodjarusawad T, Phromyothin D. Electrochemical sensor: Preparation technique based on electronic tongue in fragrance. Mater Today Proc [Internet]. 2017;4(5):6410-4. Available from: http://dx.doi.org/10.1016/j.matpr.2017.06 .146

2. Casteleiro-Roca JL, Calvo-Rolle JL, Meizoso-Lopez MC, Piñón-Pazos A, Rodríguez-Gómez BA. New approach for the QCM sensors characterization. Sensors Actuators, A Phys. 2014;207:1-9.

3. Bearzotti A, Macagnano A, Papa P, Venditti I, Zampetti E. A study of a QCM sensor based on pentacene for the 
detection of BTX vapors in air. Sensors Actuators, B Chem [Internet]. 2017;240:1160-4. Available from: http://dx.doi.org/10.1016/j.snb.2016.09.0 97

4. Jazuly AT Al. Pengujian Karakteristik dari 16 Array Sensor Lidah Elektronika untuk Identifikasi Empa Rasa Dasar. UIN Maulana Malik Ibrahim Malang; 2016.

5. Nur M, Marhaendrajaya I, Sugito, Windarti T, Arnelli, Hastuti R. Pengayaan Yodium dan Kadar $\mathrm{NaCl}$ pada Garam Krosok Enrichment of Iodium and Sodium Chloride in the Traditional Salt become. J Sains dan Mat. 2013;21(1):1-6.

6. Toko K. Electronic Sensing of Tastes. Electroanalysis. 1998;10(10):657-69.

7. Hidayat AS, Rokhmat M, Si M, Qurthobi A. Pengaruh Suhu dan Kecepatan Putar Spin Coating Terhadap Kinerja Sel Surya Organik Berbahan Dasar TiO 2. ePreceding Eng. 2014;1(1):497-510.

8. Novaetech. OpenQCM [Internet]. 2016 [cited 2017 Sep 20]. Available from: http://openqcm.com/openQCM/

9. Tazi I, Choiriyah A, Siswanta D, Triyana K. Detection of Taste Change of Bovine and Goat Milk in Room Ambient Using Electronic Tongue. Indonesian J. Chem. 2017;17(3):422-30. 